\title{
酸抽出一原子吸光法によるヒト胎盤中の亜鉛，銅，鉄， カルシウム及びマンガンの定量
}

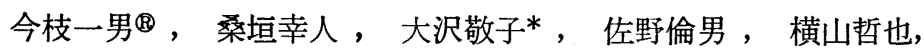 \\ 堤 紀夫，大谷良樹，田村宏平，横田 瞱**
}

(1984 年 3 月 24 日受理)

\begin{abstract}
生体試料中の微量金属を原子吸光法で測定する際の前処理として，酸で微量金属を抽出する方法の検 討を行った. 試料からの微量金属の抽出は $0.5 \mathrm{M}$ 硫酸又は $1 \mathrm{M}$ 硝酸を加光混和し, $60^{\circ} \mathrm{C} 60$ 分間振 り混ぜ後遠心分離し, 上澄みを原子吸光分析した。 ヒト胎盤, NBS 標準試料 (Bovine Liver) に本法を 適用し, テフロン内蔵容器を用いる湿式灰化法の測定值と比較した. 亜鉛, 銅, カルシウム及びマンガ ンの測定值は両方法がよく一致し満足な結果が得られた。しかし鉄は抽出法がやや低い值となった。七 卜胎盤では, 粉末化することにより高い抽出率が得られた。酸抽出法は特殊な容器を必要とせず, 簡 易，迅速な点から，多くの試料を同時処理するのに有用な方法であると考えられた.
\end{abstract}

\section{1 緒 言}

微量金属は重金属沙環境污染1)，又生体内に招い て多くの酵素活性に関与すること2)などから，その動態 に関心がもたれている.薬学，医学の分野での各種疾患 との関連，例党ば高カロリー輸液による亜鉛欠乏症3)， 味覚障害と亜鉛4)，小児及び未熟児での銅，亜鉛欠乏 症ら)などが報告されている.

血液, 尿中の微量金属は比較的簡単飞測定され，特に ヒト血清の場合は, 水での単純希积6) や除タンパクする こど)により測定が可能であり多くの報告がなされてい る. しかし組織内微量金属の測定は, あらかじめ試料を 分解して溶液状態とし, 主に原子吸光法で行われ, 多く の前処理が報告されている．試料の分解法として乾式灰 化法8) があるが，一部金属の揮散，不溶性灰分や容器一 の吸着など問題がある.そこで低沸点元素の揮散による 損失を防止できる，プラズマ低温灰化法9)が行われてい る. 従来の湿式分解法 ${ }^{10}$ ) は再現性もよく広く用いられて いるが, 酸化分解剤として硫酸, 硝酸, 過塩素酸, 過酸 化水素などの使用による金属の污染や，分解に長時間を 要する場合る多い，更に，テフロン製容器内蔵の密閉容

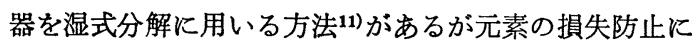

* 星薬科大学 : 142 東京都品川区嚄原 2-4-41

** 国立大蔵病院臨床研究部：157 東京都世田谷区大 蔵 2-10-1
有効である. 以上の前処理法は, 元素の損失, 分析操作 に長い時間を要したり, 高価な特殊器具を必要とするな ぞ問題点がある. その他これらの分解法を用いない組織 内微量金属の測定として, David ${ }^{12)}$ は塩酸を用いてラッ 卜組織内マンガンを, Keeling ら ${ }^{13)}$ は塩酸でヒト白血球 中亜鉛を, Hinner 14) は硝酸で NBS 標準試料中の微量 金属を抽出後分析し良い結果を得ている. しかしこれら の酸による金属元素の抽出条件の検討は十分には行われ ていない。

生体組織中の金属の測定は, 多数の試料を分析する必 要があることから, 簡便でかつ精度の良い分析法が望ま れる. そこでヒト胎盤中微量金属の分析を行ら目的で NBS 標準試料を用いて, 各種酸 (硫酸, 硝酸, 塩酸, 過塩素酸）による抽出法について, 諸条件の検討を行っ た. 酸抽出一原子吸光分析法を用いた簡便で迅速な定量 法を確立し, 本法をと卜胎盤試料に適用し, 亜鉛, 銅, 鉄，カルシウム及びマンガンの定量を行った.

\section{2 実験}

NBS 標準試料, ヒト胎盤試料の湿式分解にはテフロ ン容器内蔵ボンブ（容量 $23 \mathrm{ml}, 70 \mathrm{ml}$, Uniseal Decomposition Vassels Ltd., Haifa, Israel) を用いた. 凍 結乾燥には日本フリーザー社製冷凍真空乾燥機 F-20を 用いた。インキュベーターは大洋科学工業社製を用い た. 遠心分離機は冷却小型多本架遠心機 H-103RS, 国 産遠心機社製を用いた。原子吸光分析装置は，島津製作 
所製 AA-640-01 型原子吸光光度計を用い，空気-アセ チレンフレームにより測定した. 光源は浜松ホトニクス 社製中空陰極ランプ及び重水素ランブを用いた．分析線 波長は要鉛 $213.9 \mathrm{~nm}$ ，鉄 $248.3 \mathrm{nm，マンガン} 279.5$ $\mathrm{nm}$ ，銅 $324.7 \mathrm{nm，カルシウム} 422.7 \mathrm{~nm}$ を用いた.

\section{2 試 薬}

ランタン溶液 : 塩化ランタン $0.1 \mathrm{M}$ 塩酸溶液, 和光 純薬工業製原子吸光分析用, ランタンとして $10 \pm 3 \%$ 含 有. 標準夜は亜鉛，鉄，マンガン，銅，カルシウム原子 吸光用金属標準液，和光純薬工業製を用時適宜希䣋し調 製した。水は純水製造装置 Milli-RQ (Millipore 社製) を通し，更に超純水装置 Milli-Q (Millipore 社製) を通 したものを直ちに用いた。

\section{3 試料の調製}

標準試料として NBS SRM-1577a Bovine Liver を 用いた. ヒト胎盘試料は分べん直後に胎盤辺縁部から採 取し，直ちに冷生理食塩水で脱血後洗浄した。 これを 24 時間凍結乾燥し, 試験管中でテフロン製スパーテル を用いて粉末化した後 60 ×ッシュのポリプロピレン製 網を通して均一化し，ヒト胎盤試料とした．ひょう量 前に NBS 標準試料は指示どおり, 又ヒト胎盤試料は $85^{\circ} \mathrm{C}, 4$ 時間, 乾燥し恒量とした.

\section{$2 \cdot 4$ 操作法}

テフロソ容器内蔵ボンブを用いた試料分解法 : 乾燥器 中 $120^{\circ} \mathrm{C}$ で 30 分間あらかじめ加温したテフロン容器 内蔵ボンブにヒト胎盤, NBS 標準試料約 $250 \mathrm{mg}$ を精 密に量り取り, 濃硝酸 $0.8 \mathrm{ml}$, 過塩素酸 $0.2 \mathrm{ml}$ を加 え, $120^{\circ} \mathrm{C}$ で 80 分間加温し試料を分解する. 冷却後 内容物を水 $1.0 \mathrm{ml}$ で三角フラスコに洗い出し, 蒸発乾 固させ水 $1.0 \mathrm{ml}$ を加えて試料溶液とした。
標準操作法 : NBS 標準試料及び ヒト胎盤試料から微 量金属元素を酸で抽出する方法の概略を Fig. 1 亿示 す. 試料約 $250 \mathrm{mg}$ を試料管に精密に量り取り, $1 \mathrm{M}$ 硝 酸又は $0.5 \mathrm{M}$ 硫酸 $4.0 \mathrm{ml}$ を加兄, よく混和させる. 次に $60^{\circ} \mathrm{C}$ 恒温槽中で 30 分間振り混ぜた後, 酸抽出液 中に抽出された微量金属が試料中のタンパク質などと再 結合するのを防止するため, $35^{\circ} \mathrm{C}$ に保った遠心分離機 で遠心分離 (3000 rpm, $10 \mathrm{~min}$ )を行い, 上澄みを速や かに別の容器に移す．次に各金属元素の測定は, 上澄み を適宜希釈し，飯田ら ${ }^{15)}$ の一滴法を用いて原子吸光法で 分析する.

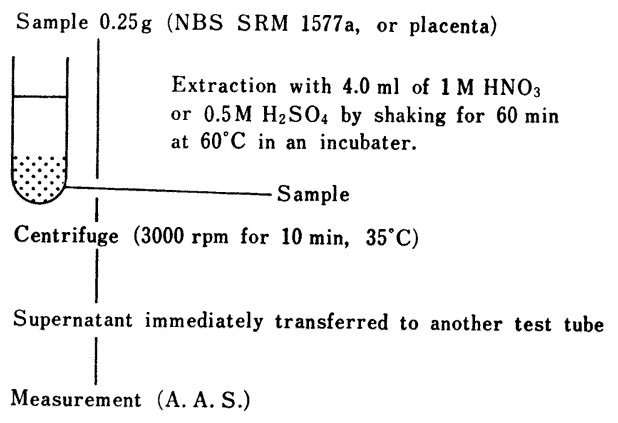

Fig. 1 Outline of extraction procedure

\section{3 結果及び考察}

\section{1 定量条件の検討}

3.1.1 酸及び濃度の検討 2.4 の抽出標準操作を行 う際に用いる酸として, 硫酸, 硝酸, 塩酸, 過塩素酸及び硫 酸-硝酸 $(0.5 \mathrm{M}: 1 \mathrm{M})$ 混液について検討した. その結果 を Table 1 に示す.マンガン,カルシウムは硫酸が $0.5 \mathrm{M}$ ， その他の酸では $1 \mathrm{M}$ の濃度で NBS 標準試料保証值と良

Table 1 Concentration of metal extracted from NBS Bovine Liver with hydrochloric acid, perchloric acid, sulfuric acid, and nitric acid

\begin{tabular}{|c|c|c|c|c|c|c|}
\hline \multicolumn{2}{|c|}{ Acid } & \multirow{2}{*}{$\frac{\begin{array}{c}\mathrm{Zn} \\
(123 \pm 8) \dagger\end{array}}{109.6}$} & \multirow{2}{*}{$\frac{\begin{array}{c}\mathrm{Cu} \\
(158 \pm 7) \dagger\end{array}}{108.9}$} & \multirow{2}{*}{$\frac{\begin{array}{c}\mathrm{Fe} \\
(194 \pm 20) \dagger\end{array}}{135.1}$} & \multirow{2}{*}{$\frac{(9.9 \pm 0.8) \dagger}{10.3}$} & \multirow{2}{*}{$\frac{\begin{array}{c}\mathrm{Ca} \\
(120 \pm 7) \dagger\end{array}}{120.7}$} \\
\hline $\mathrm{HCl}$ & $1 \mathrm{M}$ & & & & & \\
\hline & $3 \mathbf{M}$ & 109.6 & 114.2 & 140.0 & 9.8 & 123.0 \\
\hline \multirow[t]{2}{*}{$\mathrm{HClO}_{4}$} & $1 \mathrm{M}$ & 127.5 & 73.7 & 105.9 & 10.5 & 121.3 \\
\hline & $3 \mathrm{M}$ & 126.1 & 62.3 & 116.1 & 9.8 & 111.3 \\
\hline \multirow[t]{3}{*}{$\mathrm{H}_{2} \mathrm{SO}_{4}$} & $0.5 \mathrm{M}$ & 120.9 & 163.6 & 170.9 & 8.4 & 112.9 \\
\hline & $1.5 \mathrm{M}$ & 117.9 & 159.1 & 168.2 & 9.8 & 117.6 \\
\hline & $3 \mathrm{M}$ & 118.0 & 153.6 & 155.8 & 9.8 & 124.7 \\
\hline \multirow[t]{2}{*}{$\mathrm{HNO}_{3}$} & $1 \mathrm{M}$ & 116.4 & 137.2 & 95.8 & 9.4 & 116.2 \\
\hline & $3 \mathrm{M}$ & 111.6 & 142.9 & 147.0 & 9.1 & 113.5 \\
\hline \multicolumn{7}{|c|}{$\mathrm{H}_{2} \mathrm{SO}_{4}: \mathrm{HNO}_{3}$} \\
\hline \multicolumn{2}{|c|}{$0.5 \mathrm{M}: 1 \mathrm{M}$} & 122.9 & 160.4 & 172.4 & 9.7 & 124.9 \\
\hline \multicolumn{2}{|c|}{$1 \mathrm{M}: 2 \mathrm{M}$} & - & 154.8 & 162.6 & 9.5 & 118.6 \\
\hline
\end{tabular}

Values represent the average $(\mu \mathrm{g} / \mathrm{g})$ of 3 determinations. $\dagger$ NBS certified value 
く一致した．覀鉛は塩酸ではやや低い值を示したがその 他の酸についてはほぼ一致した。銅は硫酸，硫酸一硝酸 混液は一致したが他の酸は低い值となった．鉄は硫酸, 硫酸一硝酸混液による抽出が最も高い值が得られた。こ れらの結果から, 硫酸, 硫酸-硝酸混液が最も良く, 次 に硝酸の順に抽出に適した酸であることが分かった。

次に硫酸及び硝酸の濃度を変化させ抽出率に及ぼす効 果を検討した. Table 2 に测定值及びこれの NBS 標準 試料保証值に対する百分率を示す. 硫酸による抽出の場 合,亜鉛, カルシウムは $0.25 \mathrm{M}$ で約 $100 \%$ 抽出された. マンガン，銅は $0.38 \mathrm{M}$ で約 $100 \%$ であった，鉄は $0.25 \mathrm{M}$ で約 $80 \%, 0.5 \sim 1.5 \mathrm{M}$ で約 $87 \%$ の抽出率が 得られた．硝酸では亜鉛，マンガン，カルシウムは 0.2 M で約 $100 \%$ 抽出された. 銅, 鉄は $3 \mathrm{M}$ でそれぞれ 約 $95 \%$, 約 $83 \%$ であった. 水によってこれらの金属 が抽出されるかについても検討した結果, マンガン, カ ルシウムが約 $70 \%$, 亜鉛, 銅, 鉄が約 $10 \%$ 抽出され ることが分かった.

3.1.2 抽出温度 NBS 標準試料を用いて, 硫酸及 び硝酸で金属を抽出するときの温度について検討した。
20〜 60 ${ }^{\circ} \mathrm{C}$ に括ける測定値及びこれの NBS 標準試料保 証值に対する百分率を Table 3 に示す. $0.5 \mathrm{M}$ 硫酸て は亜鉛, マンガンは $20{ }^{\circ} \mathrm{G}$ で約 $100 \%$ 抽出された．銅 は $20^{\circ} \mathrm{C}$ で約 $80 \%, 40{ }^{\circ} \mathrm{C}$ で約 $100 \%$ 抽出された。

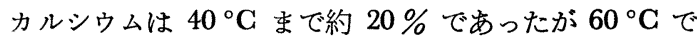
は約 $100 \%$ の抽出率となった。鉄は温度を上昇させる ことにより増加し $60^{\circ} \mathrm{G}$ で約 $88 \%$ であった. そこで 抽出を 3 時間行ったが増加せず良好な抽出率は得られな かった. 以上の結果より以後の実験では $0.5 \mathrm{M}$ 硫酸及び $1 \mathrm{M}$ 硝酸を用い, 温度 $60^{\circ} \mathrm{C}$ で 1 時間抽出を行うこと とした.

3.1.3 金属添加による回収率 NBS 標準試料に濃 度既知の金属標準液を各元素ごとに添加する．良く混和 後凍結乾燥したものについて標準操作を行い，回収率を 求め, その結果を Table 4 と示す. 硫酸及び硝酸抽出 ともに約 $92 \%$ 以上の良好な回収率が得られた。

\section{2 密閉容器分解法との比較}

NBS 標準試料を用い，硫酸及び硝酸抽出による本法 と, テフロン製試料分解容器を用いた密閉容器分解法を

Table 2 Relationship between extraction ratio to NBS certified value and concentration of nitric acid or sulfuric acid

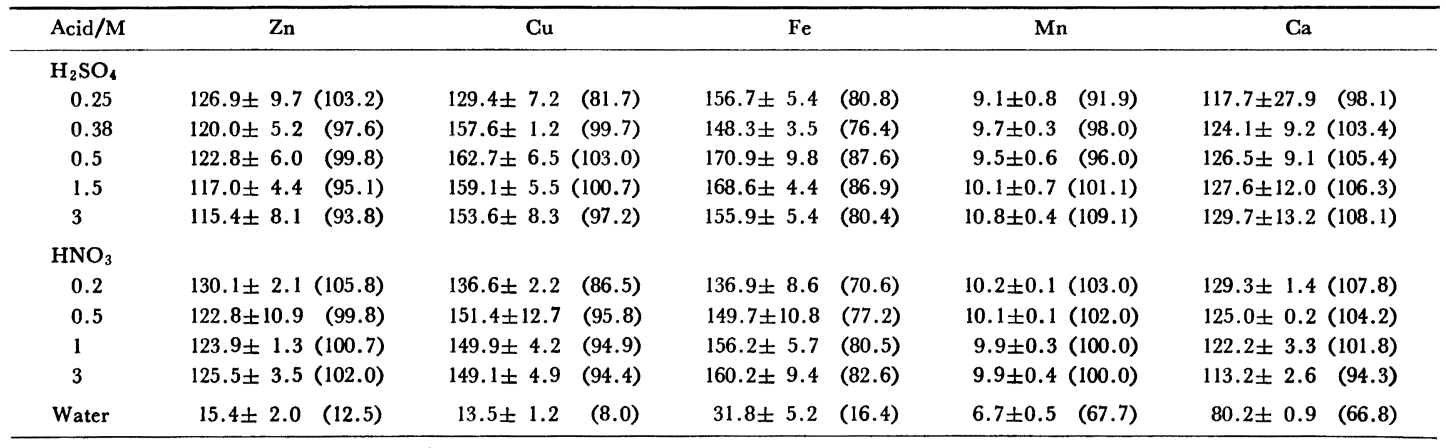

Values represent the mean \pm S. D. $(\mu \mathrm{g} / \mathrm{g})$ of 5 determinations. Numbers in parenthesis represent the percentages to NBS certified value.

Extraction was performed at $60^{\circ} \mathrm{C}$ for $60 \mathrm{~min}$.

Table 3 Relationship between extraction temperature and extraction ratio to NBS certified value

\begin{tabular}{|c|c|c|c|c|c|}
\hline & $\mathrm{Zn}$ & $\mathrm{Cu}$ & $\mathrm{Fe}$ & $\mathrm{Mn}$ & $\mathbf{C a}$ \\
\hline \multicolumn{6}{|l|}{$\mathrm{H}_{2} \mathrm{SO}_{4}$} \\
\hline $20^{\circ} \mathrm{C}$ & $125.3 \pm 2.2(101.9)$ & $126.0 \pm 0.5 \quad(79.7)$ & $82.1 \pm 3.8(42.3)$ & $10.1 \pm 0.3(102.0)$ & $26.1 \pm 1.4 \quad(21.8)$ \\
\hline $40 "$ & $126.4 \pm 2.6(102.8)$ & $163.1 \pm 3.2(103.2)$ & $147.8 \pm 7.4(74.1)$ & $10.7 \pm 0.2(108.1)$ & $25.0 \pm 1.1$ \\
\hline $60 "$ & $122.8 \pm 6.0$ & $162.7 \pm 6.5(103.0)$ & $170.9 \pm 9.8(87.9)$ & $9.5 \pm 0.6$ & $126.5 \pm 9.1(105.4)$ \\
\hline \multicolumn{6}{|l|}{$\mathrm{HNO}_{3}$} \\
\hline $20^{\circ} \mathrm{C}$ & $124.1 \pm 1.7(100.9)$ & $100.5 \pm 2.4$ & $67.2 \pm 9.2(34.6)$ & $9.9 \pm 0.3(100.0)$ & $115.7 \pm 3.5$ \\
\hline $40 " \prime$ & $124.5 \pm 2.3(101.2)$ & $129.2 \pm 2.7$ & $119.8 \pm 1.6(61.8)$ & $9.7 \pm 0.2 \quad(98.0)$ & $124.1 \pm 9.1(103.4)$ \\
\hline $60 " 1$ & $126.8 \pm 1.5(103.1)$ & $136.1 \pm 4.1$ & $164.1 \pm 6.7(84.6)$ & $10.4 \pm 0.6(105.1)$ & $124.1 \pm 8.4$ \\
\hline
\end{tabular}

Values represent mean \pm S. D. of 5 determinations. Numbers in parenthesis represent the percentages to NBS certified value. Extraction was performed for $60 \mathrm{~min}$ with $0.5 \mathrm{M}$ sulfuric acid or $1 \mathrm{M}$ nitric acid. 
Table 4 Recoveries of metals from NBS Bovine Liver by extraction method with $0.5 \mathrm{M}$ sulfuric acid or $1 \mathrm{M}$ nitric acid

\begin{tabular}{|c|c|c|c|c|c|}
\hline \multirow{2}{*}{\multicolumn{2}{|c|}{$\begin{array}{c}\text { Amount added/ } \\
(\mu \mathrm{g} / \mathrm{g})\end{array}$}} & \multicolumn{2}{|c|}{$0.5 \mathrm{M} \mathrm{H}_{2} \mathrm{SO}_{4}$} & \multicolumn{2}{|c|}{$1 \mathrm{M} \mathrm{HNO}_{3}$} \\
\hline & & \multirow{2}{*}{$\frac{\text { Analytical value } /(\mu \mathrm{g} / \mathrm{g})}{36.0 \pm 2.0}$} & \multirow{2}{*}{$\frac{\text { Recovery, } \%}{120.0}$} & \multirow{2}{*}{$\frac{\text { Analytical value } /(\mu \mathrm{g} / \mathrm{g})}{30.5 \pm 1.4}$} & \multirow{2}{*}{$\frac{\text { Recovery, } \%}{106.7}$} \\
\hline $\mathrm{Zn}$ & 30.0 & & & & \\
\hline $\mathrm{Cu}$ & 40.0 & $36.6 \pm 2.9$ & 91.5 & $42.5 \pm 10.1$ & 106.3 \\
\hline $\mathrm{Fe}$ & 40.0 & $37.3 \pm 1.3$ & 93.3 & $48.9 \pm 12.9$ & 122.3 \\
\hline Mn & 3.0 & $2.85 \pm 0.32$ & 95.0 & $2.8 \pm 0.3$ & 93.3 \\
\hline $\mathrm{Ga}$ & 30.0 & $34.3 \pm 3.9$ & 114.3 & $31.5 \pm 1.1$ & 105.0 \\
\hline
\end{tabular}

A constant concentration of metal was added to NBS Bovine Liver to clarify the recovery by extraction method. Values represent the mean \pm S. D. $(n=5)$. Extraction was performed at $60^{\circ} \mathrm{C}$ for $60 \mathrm{~min}$.

Table 5 Concentrations of metals extracted from NBS Bovine Liver with $0.5 \mathrm{M}$ sulfuric acid and $1 \mathrm{M}$ nitric acid

\begin{tabular}{|c|c|c|c|c|c|c|c|}
\hline \multirow{2}{*}{ Metals } & \multicolumn{4}{|c|}{ Extraction method } & \multicolumn{3}{|c|}{ Ashing method } \\
\hline & $\begin{array}{c}\mathrm{H}_{2} \mathrm{SO}_{4} \\
(n=5)\end{array}$ & R.S.D., & $\begin{array}{l}\mathrm{HNO}_{3} \\
(n=5)\end{array}$ & R.S.D., & $\begin{array}{c}\text { Ash } \\
(n=5)\end{array}$ & R.S.D., & $\begin{array}{l}\text { NBS certified } \\
\text { value }\end{array}$ \\
\hline $\mathrm{Zn}$ & $122.8 \pm 6.0$ & 4.8 & $126.8 \pm 1.5$ & 1.2 & $119.0 \pm 3.3$ & 2.8 & $123 \pm 8$ \\
\hline $\mathrm{Cu}$ & $162.7 \pm 6.5$ & 4.0 & $136.1 \pm 4.1$ & 3.0 & $160.7 \pm 9.3$ & 5.8 & $158 \pm 7$ \\
\hline $\mathrm{Fe}$ & $170.9 \pm 9.8$ & 5.7 & $164.5 \pm 6.7$ & 4.1 & $204.1 \pm 49.0$ & 24.0 & $194 \pm 20$ \\
\hline $\mathrm{Mn}$ & $9.5 \pm 0.6$ & 6.3 & $10.4 \pm 0.6$ & 5.4 & $9.8 \pm 0.4$ & 4.1 & $9.9 \pm 0.8$ \\
\hline $\mathrm{Ca}$ & $126.5 \pm 9.1$ & 7.2 & $124.1 \pm 8.4$ & 6.8 & $117.3 \pm 10.3$ & 8.8 & $120 \pm 7$ \\
\hline
\end{tabular}

Values represent mean \pm S. D. $(\mu \mathrm{g} / \mathrm{g})$. Extraction was performed at $60^{\circ} \mathrm{C}$ for $60 \mathrm{~min}$. R.S.D. : Relative standard deviation

比較した結果を Table 5 に示す. 硫酸を用いた場合の 抽出法では亜鉛, 銅, マンガン, カルシウムが NBS 標 準試料の保証值と良く一致した值が得られた．硝酸によ る抽出法は亜鉛, マンガン, カルシウムは保証值と一致 した值となったが, 銅, 鉄はそれぞれ約 $15 \%$ 低い值と なった。それぞれの方法による測定值のばらつきをみる ために相対標準偏差 (R.S.D.) を併記したが, 硝酸抽出 はマンガンが, 又硫酸抽出法では亜鉛、マンガンがやや 大きな R.S.D. となった. しかし, 全体的に本法のほう が小さい值の R.S.D. が得られた. これは分析操作が簡 単で污染や吸着あるいは揮発による損失などが少ないた め良好な結果が得られたためと考えられる。

\section{3 実試料への適用}

抽出法をヒト胎盤試料に適用する際に，組織内微量金 属が抽出されやすい形態として, NBS 標準試料の形態 が粉末状であることを考慮して, ヒト胎盤試料の粉末化 による金属の分析值への影響について検討した，一般的 には組織試料の 細分化及び均一化は，ポッター型ホモ ジナイザー又は金属刃のホモジナイザーが用いられてい る.しかしこれらの方法では金属が試料と接触すること により混入することもある，そこで，金属による污染を 防止するため，ホモジナイザーを用いず，ヒト胎盤を凍 結乾燥後直ちにテフロンスパーテルで粉末化した. この
Table 6 Effect of pulverization on extraction efficiency from human placenta

\begin{tabular}{cccccc}
\hline \multirow{2}{*}{ Metal } & \multicolumn{2}{c}{$\begin{array}{c}0.5 \mathrm{M} \mathrm{H}_{2} \mathrm{SO}_{4}(n=3) \\
\begin{array}{c}\text { Not } \\
\text { pulverized }\end{array}\end{array}$} & Pulverized & \begin{tabular}{c}
$1 \mathrm{M} \mathrm{HNO}_{3}(n=3)$ \\
\cline { 5 - 6 } $\begin{array}{c}\text { Not } \\
\text { pulverized }\end{array}$
\end{tabular} & Pulverized \\
\hline $\mathrm{Zn}$ & 73.9 & 69.5 & 72.0 & 72.9 \\
$\mathrm{Cu}$ & 3.94 & 3.34 & - & - \\
$\mathrm{Mn}$ & 1.16 & 1.37 & 0.69 & 0.63 \\
$\mathrm{Ca}$ & 1640.4 & 2499.8 & 5316.9 & 12778.1 \\
\hline
\end{tabular}

Values represent the average $(\mu \mathrm{g} / \mathrm{g}$ dry weight) of 3 determinations. Extraction was performed at $60^{\circ} \mathrm{C}$ for $60 \mathrm{~min}$.

粉末化したものと, 未粉末 (組織片) のものにつき標準 操作を行い比較した結果を Table 6 に示す. 亜鉛, 銅, マンガンは粉末化の影響はみられず, 試料が末粉末でも 抽出が可能と考えられた. しかしカルシウムは粉末化し た試料のほらが高い值が得られ，粉末化する必要のある ことが分かった.

ヒト胎盤試料について本法を適用し, 密閉容器分解法 による測定值とを比較した結果を Table 7 に示す. 硫 酸抽出では亜鉛, 銅, マンガン, カルシウムは良く一致 した值であった. 鉄は NBS 標準試料について比較した 場合と同様に本法のほうが低い測定值となった。硝酸に よる抽出は銅及び鉄が低い值を示した.

本研究に拈いて適用した実試料はヒト胎盤のみである が, 今後の検討により他組織への適用も可能となり, 本 
Table 7 Comparison of metal concentration in human placenta between extraction method and ashing method

\begin{tabular}{|c|c|c|c|c|}
\hline Metal & $\begin{array}{c}0.5 \mathrm{M} \mathrm{H}_{2} \mathrm{SO}_{4} \\
\text { extraction } \\
(n=3)\end{array}$ & $\begin{array}{c}\text { Ashing } \\
(n=2)\end{array}$ & $\underset{\substack{1 \mathrm{M} \mathrm{HNaction} \\
\text { extraction }}}{\left.\mathrm{H}_{3}=12\right)}$ & $\begin{array}{l}\text { Ashing } \\
(n=12)\end{array}$ \\
\hline $\mathrm{Zn}$ & $69.4 \pm 4.0$ & $67.9 \pm 0.2$ & $71.9 \pm 9.1$ & $70.9 \pm 8.6$ \\
\hline $\mathrm{Cu}$ & $3.4 \pm 0.35$ & $3.9 \pm 0.18$ & $4.9 \pm 2.0$ & $5.5 \pm 1.4$ \\
\hline $\mathrm{Fe}$ & $144.7 \pm 31.2$ & $392.3 \pm 61.3$ & $249.6 \pm 38.0$ & $396.5 \pm 159.0$ \\
\hline $\mathrm{Mn}$ & $1.37 \pm 0.13$ & $1.38 \pm 0.15$ & $0.63 \pm 0.15$ & $0.64 \pm \quad 0.15$ \\
\hline $\mathrm{Ca}$ & $2259.0 \pm 320.6$ & $2499.8 \pm 382.3$ & $16109.0 \pm 13190.4$ & $15465.0 \pm 12464.3$ \\
\hline
\end{tabular}

Values represent the mean $\pm S$. D. ( $\mu \mathrm{g} / \mathrm{g}$ dry weight). Extraction was performed at $60^{\circ} \mathrm{C}$ for $60 \mathrm{~min}$.

法は生体内微量金属代謝解明の有用な手段になると考え られる。

$$
\left(\begin{array}{l}
1983 \text { 年 } 10 \text { 月, 日本分析化学会 } \\
\text { 第 } 32 \text { 年会において一部発表 }
\end{array}\right)
$$

\section{文献}

1) W. John : Sci. Total Environ., 27, 21 (1983).

2）不破敬一郎：“生体之重金属”, p. 120 (1982), (講談社).

3) 岡田 正, 高木洋治, 坂倉交夫, 佐谷 稔, 曲直 部寿夫, 飯田喜戸, 野瀬 莘, 谷垣武彦, 岩崎雅 行，笠原伸元：医学のあゆみ，92，436 (1975).

4) 富田 寬, 石井泰平, 都川正之：微量金属代謝, 1, $61(1975)$.

5）松田一郎，東 明正：日本小児科学会雑誌，87, 710 (1983).

6) 前田英介, 吐田友紀子, 中 甫：衛生検査, 13, 687 (1977).

7) J. Versieck, R. Cornelis : Anal. Chim. Acta, 116, 217 (1980).

8）河島達郎，山本俊夫，甲田善生：分化， 31， T 10 (1982).

9) 平間元博, 藤岡保範, 恩村雄太 : 臨床検查, 21, 143 (1977).

10）田口 正, 高城裕之, 戸田昭三, 岩島 清, 山県 登：分化, 30, T1 (1981).

11）坂田昌弘, 下田 修: 分化, 31, T81 (1982)。

12) I. P. David : Anal. Chem., 51, 2086 (1979).

13) P. W. N. Keeling, R. B. Jones : Gut, 21, 561 (1980).

14) T. A. Hinners : Frsenius' Z. Anal. Chem., 277, 377 (1975).

15）内田哲男, 小島 功, 飯田忠三 : 分化, 27, T44 (1978).

象

Determination of zinc, copper, iron, calcium, and manganese in human placenta by acid extraction-atomic absorption spectrometry. Kazuo Imaeda, Yukihito KuWAgaki, Keiko OHSAWA*, Michio Sano, Tetsuya Yokoyama, Toshio Tsutsumi, Yoshiki Ohtani, Kohei Tamura, and Akira Yokota**
(*Hoshi University, 2-4-41, Ebara, Shinagawa-ku, Tokyo, 142; **Department of Clinical Research, National Okura Hospital, 2-10-1, Okura, Setagaya-ku, Tokyo, 157)

To determine the trace metal in the biological samples, an extraction method using mineral acid was examined. Sulfuric acid, nitric acid, hydrochloric acid, perchloric acid, and sulfuric acid-nitric acid mixture (1: $1, \mathrm{v} / \mathrm{v})$ were compared. As a result, sulfuric acid, nitric acid, and sulfuric acid-nitric acid mixture were found to be suitable for the extraction. NBS SRM 1577a Bovine Liver and human placenta were used. In the case o the human placenta, the sample was washed by cold saline. And after lyophilization for $24 \mathrm{~h}$, the placenta for the sample was pulverized $(60 \mathrm{mesh})$ by Teflon spatula. Four $\mathrm{ml}$ of $0.5 \mathrm{M}$ sulfuric or $1 \mathrm{M}$ nitric acid was added to about $250 \mathrm{mg}$ of NBS standard sample and the human placenta, and was placed in a shaker for $1 \mathrm{~h}$ at $60^{\circ} \mathrm{C}$. The supernatant was separated by centrifugation for $10 \mathrm{~min}$ ( 3000 r.p.m.) at $35^{\circ} \mathrm{C}$. The aliquot of the supernatant was diluted, and the concentrations of trace metals in the sample were measured by atomic absorption spectrophotometry. $\mathrm{Mn}, \mathrm{Zn}, \mathrm{Ca}$, $\mathrm{Cu}$, or $\mathrm{Fe}$ was added to NBS standard sample at the concentrations of $3,30,30,40$, and $40 \mu \mathrm{g} / \mathrm{g}$, respectively, and the recovery was examined. The recoveries of these metals(about $92 \%$ ) were good enough for practical analysis. The results of the acid extraction method were compared with those of the wet digestion in the Teflon-lined bomb. The analytical values of $\mathrm{Zn}, \mathrm{Cu}$, $\mathrm{Ca}$, and $\mathrm{Mn}$ by the extraction method coincided with those of the ashing method, while the value of $\mathrm{Fe}$ was lower in the extraction method. In conclusion, the acid extraction method was both acceptable and practical for the determination of the trace metal contained in a great number of biological samples because of its simple procedure.

(Received March 24, 1984)

\section{Keyword phrases}

extraction of trace metals by sulfuric or nitric acid; atomic absorption spectrophotometry; determination of zinc, copper, iron, calcium, and manganese in human placenta. 